\title{
TRÁFEGO DE MÁQUINAS AGRÍCOLAS E ALTERAÇÕES DE BIOPOROS EM ÁREA SOB POMAR DE LARANJA ${ }^{(1)}$
}

\author{
Herdjania Veras de Lima ${ }^{(2)}$, Cláudia Liane Rodrigues de Lima ${ }^{(3)}$, \\ Tairone Paiva Leão ${ }^{(4)}$, Miguel Cooper ${ }^{(5)}$, Alvaro Pires da Silva ${ }^{(5)}$ \\ \& Ricardo Espíndola Romero ${ }^{(2)}$
}

\begin{abstract}
RESUMO
O estudo micromorfológico permite observar detalhadamente todas as modificações causadas na estrutura e no espaço poroso do solo, impostas pelo cultivo e pelo tráfego de máquinas agrícolas. Este trabalho testou a hipótese de que a compactação causada pelo tráfego de máquinas influi, diferencialmente, na forma e na distribuição das classes de poros, os quais podem ser utilizados como indicadores da qualidade do solo. O objetivo deste trabalho foi avaliar e quantificar, por meio de estudos micromorfológicos, as modificações na porosidade oriunda da atividade biológica (bioporos) em um Latossolo VermelhoAmarelo sob pomar de laranja submetido ao tráfego de máquinas. Amostras indeformadas foram coletadas na superfície (0-12 cm) de uma área sob pomar de laranja, abrangendo as posições: entrerodado (ER), rodado (R) e projeção da copa ( $P C)$, utilizado, como testemunha, um perfil sob mata. Os resultados mostraram que o aumento na diversidade de poros está diretamente relacionado com os processos de degradação da estrutura do solo e que o estudo da ocorrência das classes de poros mostrou-se mais eficiente na identificação da compactação do solo em estádios iniciais que os dados de densidade do solo.
\end{abstract}

Termos de indexação: Latossolo Vermelho-Amarelo, micromorfologia, compactação do solo, distribuição do espaço poroso.

\footnotetext{
(1) Recebido para publicação em agosto de 2004 e aprovado em julho de 2005.

(2) Doutoranda e Professor do Departamento de Ciências do Solo da Universidade Federal do Ceará - UFC. Bloco 807, Campus do Pici, CEP 60455-760 Fortaleza (CE). Bolsista do CNPq. E-mail: hvlima@ufc.br; reromero@ufc.br

(3) Doutoranda do Centro de Ciências Rurais da Universidade Federal de Santa Maria - UFSM. Faixa de Camobi, Km 9, Campus Universitário, CEP 97105-900 Santa Maria (RS). Bolsista do CNPq. E-mail: clrlima@mail.ufsm.br

(4) Doutorando do Department of Earth and Planetary Sciences, University of Tennessee Knoxville, 1412 Circle Drive, 37996-1410, Knoxville, TN, USA. E-mail: trpleao@hotmail.com

(5) Professor do Departamento de Solos e Nutrição de Plantas, Escola Superior de Agricultura "Luiz de Queiroz" - ESALQ/USP. CEP 13400-970 Piracicaba (SP). E-mail: mcooper@esalq.usp.br; apisilva@esalq.usp.br
} 


\title{
SUMMARY: AGRICULTURAL MACHINERY TRAFFIC AND ALTERATIONS IN BIOPORES UNDER AN ORANGE ORCHARD
}

\begin{abstract}
Soil micromorphological studies enable a detailed observation of the modifications in soil pore structure and space imposed by cultivation and agricultural machinery traffic. This study tested the hypothesis that compaction caused by machinery affects the form and class distribution of pores in a distinct way and that such alterations can be used as soil quality indicators. The objectives of this study were to evaluate and quantify, through micromorphological studies, the modifications in porosity caused by biological activity (biopores) in a Red-Yellow Latosol (Oxisol) under an orange orchard subjected to machinery traffic. Undisturbed samples were collected from the surface soil layer $(0-12 \mathrm{~cm})$ in the following positions: in-between wheel tracks (ER), wheel tracks $(R)$ and plant canopy projection (PC). For comparison purposes, samples were also collected from a soil profile under natural vegetation. Results showed that the increase in pore diversity is directly related to the process of soil structure degradation. The study of pore classes was more effective to identify soil compaction in its initial state than soil density data.
\end{abstract}

Index terms: Oxisol, micromorphology, soil compaction, pore space distribution.

\section{INTRODUÇÃO}

A micromorfologia do solo é uma ferramenta que permite observar os componentes estruturais do solo na sua forma natural, possibilitando melhor visualização do comportamento da estrutura e do espaço poroso do solo em áreas sob processo de degradação. De acordo com Mermut et al. (1992), a observação direta do espaço poroso é importante para se compreender como as práticas de manejo afetam a qualidade física do solo.

O espaço poroso do solo é formado por vários processos que resultam em poros de diferentes formas e tamanhos. Os poros tipo empacotamento e as fissuras são considerados poros estruturais (Ringrose-Voase, 1987), por apresentarem definição da unidade estrutural do solo; já os poros tipo cavidades, canais, câmaras e vesículas não têm relação com as unidades estruturais, podendo ocorrer dentro ou através das mesmas. Os poros estruturais são resultantes do cultivo, tráfego, tempo e da atividade biológica do solo, sendo considerados bons indicadores dos processos de compactação (Richard et al., 2001).

Curmi et al. (1994), estudando a degradação da estrutura em solos cultivados, mostraram que os poros texturais, provenientes do arranjamento das partículas elementares do solo, não são afetados pelo processo de compactação; os poros estruturais têm seu tamanho e formato reduzido, e os poros provenientes da atividade biológica (bioporos), tipo canais, desaparecem, quando submetidos a processos de compactação. O monitoramento da distribuição das classes de poros e o estudo da permanência dos bioporos em áreas sob cultivo são de grande relevância, visto que a redução destes pode diminuir a condutividade hidráulica dos solos saturados (Curmi et al., 1994) e a queda da produção agrícola (Miedema, 1997; VandenBygaart et al., 1999).
Estudos realizados em área sob plantio direto mostraram que os bioporos, apesar de representarem pequeno volume em relação ao volume total de poros, são altamente funcionais e reduzem a resistência do solo à penetração das raízes (Genro Júnior et al., 2004).

De acordo com Ringrose-Voase (1991), entendese por poros oriundos da atividade biológica (ou bioporos) aqueles originados pela flora e fauna do solo, como, por exemplo, os poros tipo canais e câmaras.

A presença de determinados tipos de poros revela que fatores externos à organização das partículas do solo têm influenciado a sua formação. Exemplo disso são os poros tipo vesículas, os quais têm sua formação atribuída a processos de compactação, visto que são normalmente formados pela reorganização das unidades estruturais do solo, causada pelo manejo e por bolhas de ar presas durante o processo de encrostamento superficial (Mermut, 1992). Outro exemplo de poros provenientes da alteração da estrutura, por meio da compactação, são as cavidades. Ringrose-Voase \& Bullock (1984) sugerem que a formação das cavidades está relacionada com o adensamento ou com a compactação dos poros de empacotamento, mas, segundo Brewer (1976), as cavidades são formadas a partir da freqüente atividade da fauna no solo.

Vários trabalhos caracterizam, micro e, principalmente, macromorfologicamente, os impactos causados pelo manejo em áreas agrícolas (Pagliai, 1987; Curmi et al., 1994), porém poucos investigaram o comportamento dos poros originados pela atividade biológica nesses sistemas de manejo. Curmi et al. (1994), estudando o efeito do uso agrícola na modificação da estrutura e da porosidade do solo, verificaram que a compactação induzida pelo cultivo afetou, de forma diferencial, cada classe de poro, sendo 
os poros oriundos da fauna e da flora os mais afetados.

Com base nessas informações, este trabalho procurou testar a hipótese de que a compactação causada pelo tráfego de máquinas afeta, diferencialmente, a forma e a distribuição das classes de poros, os quais podem ser utilizados como indicadores da qualidade do solo.

O objetivo deste estudo foi avaliar e quantificar, por meio de estudos micromorfológicos, as modificações na porosidade oriunda da atividade biológica (bioporos) em um Latossolo VermelhoAmarelo sob pomar de laranja submetido ao tráfego de máquinas agrícolas.

\section{MATERIAL E MÉTODOS}

Foram estudados dois perfis de solo localizados no Campus Experimental da ESALQ/USP em Piracicaba (SP). O perfil 1 (P1) foi situado no terço médio da paisagem, na entrelinha de um pomar de laranja Pêra (Citrus sinensis (L.) Osbeck) sobre porta-enxerto de limão Cravo (Citrus limonia (L.) Osbeck), plantado no mês de março do ano de 1991. O perfil 2 (P2), enquadrado na mesma classe taxonômica do P1, foi utilizado como testemunha, estando situado em área sob mata do tipo floresta estacional semidecídua.

A área total do pomar de laranja é de $24.128 \mathrm{~m}^{2}$, com espaçamento de $8 \times 4 \mathrm{~m}$. Sua entrelinha é trafegada mecanicamente por tratores e implementos agrícolas, três vezes ao ano para fins de adubação, aplicação de herbicidas e roçagem. Em todas as operações, foi utilizado um trator modelo
MF 275 (4 x 2) com peso de $3.900 \mathrm{~kg}$ e pneus dianteiros do tipo 7.5-16F2, cuja pressão de inflação do ar era de $240 \mathrm{kPa}$, os pneus traseiros, tipo 18.4-30R1, utilizavam uma pressão de $96,5 \mathrm{kPa}$ (Lima et al., 2004).

Para determinar as características morfológicas das áreas estudadas, foram abertas duas trincheiras, correspondentes aos perfis P1 e P2, ambos classificados como Latossolo Vermelho-Amarelo (Quadro 1). Na área sob pomar (P1), a trincheira foi aberta com aproximadamente $4 \mathrm{~m}$ de comprimento x 2 m de profundidade, abrangendo as posições: projeção da copa $(\mathrm{PC})$, rodado $(\mathrm{R})$ e entrerodado (ER). No perfil P2, área sob mata, a trincheira foi aberta com as dimensões de 2 × 1,5 x 2 m.

A descrição morfológica, segundo Lemos \& Santos (1996), e a coleta de solo para a caracterização de ambos os perfis foram realizadas no mês de março de 2002. Para a confecção de lâminas delgadas foram coletadas amostras indeformadas em caixa do tipo Kubiena (12 x 7 × $6 \mathrm{~cm})$, na camada superficial de 0-0,12 m no P1, abrangendo as posições PC, R e ER, as quais estavam distantes do tronco 1,5, 3,5 e $4 \mathrm{~m}$, respectivamente. Para efeito de comparação quanto às alterações causadas na camada superficial do solo, pelo uso de máquinas agrícolas, foi coletada uma amostra na mesma profundidade em área sob mata (P2), a qual serviu como testemunha.

Após a coleta, as amostras foram secas em estufa a $40{ }^{\circ} \mathrm{C}$, durante uma semana, e impregnadas sob vácuo com resina poliéster (Castro, 1985). Posteriormente, foram iniciados o corte e o desbaste dos blocos para confecção das lâminas delgadas.

As descrições micromorfológicas foram feitas com

Quadro 1. Caracterização morfológica dos perfis da área sob pomar de laranja e da área sob mata

\begin{tabular}{|c|c|c|c|c|c|c|c|}
\hline \multirow{2}{*}{ Horizonte } & \multirow{2}{*}{ Profundidade } & \multicolumn{2}{|c|}{ Cor } & \multirow{2}{*}{ Estrutura(1) } & \multicolumn{2}{|c|}{ Consistência(2) } & \multirow{2}{*}{ Transição ${ }^{(3)}$} \\
\hline & & Seca & Úmida & & Seca & Úmida & \\
\hline & $\mathrm{m}$ & \multicolumn{2}{|c|}{ Munssell _ـ } & & & & \\
\hline & & \multicolumn{3}{|c|}{ P1 - Latossolo Vermelho-Amarelo (sob pomar de laranja) } & & & \\
\hline $\mathrm{Ap}$ & $0-0,10$ & $5 \mathrm{YR} 4 / 4$ & $5 Y R 3 / 3$ & md., peq./média, blocos subang. & MD & $\mathrm{F}$ & GR. e PL. \\
\hline $\mathrm{AB}$ & $0,10-0,23$ & $7,5 \mathrm{YR} 4 / 4$ & $5 \mathrm{YR} 3 / 3$ & md., peq./média, blocos subang. & MD & $\mathrm{F}$ & CL. e PL. \\
\hline $\mathrm{BA}$ & $0,23-0,43$ & $5 \mathrm{YR} 5 / 6$ & 5 YR $4 / 6$ & md., média, blocos subang. & LD & $\mathrm{F}$ & GR. e PL. \\
\hline Bw1 & $0,43-0,63$ & $5 \mathrm{YR} 5 / 6$ & $5 \mathrm{YR} 4 / 4$ & md., média, blocos subang. & $\mathrm{M}$ & $\mathrm{F}$ & CL. e PL. \\
\hline $\mathrm{Bw} 2$ & $0,63-0,81$ & $5 \mathrm{YR} 5 / 6$ & $5 \mathrm{YR} 4 / 6$ & md., média/gr., blocos subang. & $\mathrm{M}$ & $\mathrm{F}$ & CL. e PL. \\
\hline $\mathrm{Bw} 3$ & $0,81-1,80$ & 5YR 5/6 & 5YR $4 / 6$ & md., média/gr., blocos subang. & $\mathrm{M}$ & $\mathrm{F}$ & - \\
\hline \multicolumn{8}{|c|}{ P2 - Latossolo Vermelho-Amarelo (sob mata) } \\
\hline A & $0-0,10$ & 2,5 YR $3 / 2$ & $2,5 \mathrm{YR} 2,5 / 3$ & fraca, média/gr., blocos subang. & $\mathrm{LD}$ & MF & AB. e PL. \\
\hline $\mathrm{AB}$ & $0,10-0,22$ & $5 \mathrm{YR} 4 / 4$ & $5 \mathrm{YR} 3 / 4$ & fraca, média, blocos subang. & LD & $\mathrm{F}$ & CL. e PL. \\
\hline $\mathrm{BA}$ & $0,22-0,35$ & $5 Y R \quad 4 / 6$ & 5 YR $3 / 4$ & fraca, média, blocos subang. & $\mathrm{LD}$ a $\mathrm{F}$ & $\mathrm{MF}$ & DI. e PL. \\
\hline Bw1 & $0,35-0,63$ & 5YR $4 / 6$ & $5 \mathrm{YR} 4 / 4$ & md./fraca, média, blocos subang. & $\mathrm{M}$ a LD & MF & DI. e PL. \\
\hline $\mathrm{Bw} 2$ & $0,63-0,88$ & $5 Y R 4 / 6$ & $5 \mathrm{YR} 4 / 5$ & md./fraca, média, blocos subang. & LD & MF & - \\
\hline Bw3 & $0,88-1,50$ & 5YR $4 / 6$ & $5 \mathrm{YR} 4 / 5$ & - & $\mathrm{M}$ & MF & - \\
\hline
\end{tabular}

(1) md. - moderada; peq. - pequena; gr. - grande; subang. - subangulares. ${ }^{(2)} \mathrm{MD}$ - muito dura, LD - ligeiramente dura; M - macia; F - friável; MF - muito friável. ${ }^{(3)}$ GR.- gradual; PL. - plana; CL.-clara; DI.- difusa; AB. - abrupta. 
auxílio de microscópio petrográfico, usando terminologias propostas por Stoops \& Jongerius (1975), Brewer (1976) e Bullock et al. (1985). A quantificação do tamanho, forma e tipo de poros nas lâminas de solo foi realizada por meio de observações visuais, de acordo com Bullock et al. (1985).

A densidade do solo foi determinada nos mesmos pontos de amostragem dos perfis $\mathrm{P} 1$ e $\mathrm{P} 2$, na camada de $0-0,12 \mathrm{~m}$, conforme Blake \& Hartge (1986). Para tanto, foram utilizados anéis volumétricos com aproximadamente $96,2 \mathrm{~cm}^{3}$.

\section{RESULTADOS E DISCUSSÃO}

A camada de $0-0,12 \mathrm{~m}$ de ambos os perfis estudados apresentou textura franco- argilo-arenosa (Quadro 2). As análises químicas mostraram que o cultivo da laranja reduziu os teores de M.O. e P e os valores de $\mathrm{S}, \mathrm{Te}$ V. Observou-se, ainda, que as maiores reduções ocorreram na camada superficial, objeto de estudo deste trabalho. Resultados similares em pomar de laranja foram encontrados por Cintra et al. (1983) e Sanches et al. (1999).

Na posição ER (Quadro 3), a organização dos constituintes da matriz do solo apresentou-se bastante uniforme, evidenciando uma trama (contextura) do tipo porfiro-enáulica (Stoops \& Jongerius, 1975), onde o plasma, em parte, reveste as frações grosseiras e, em parte, preenche parcialmente os espaços vazios entre essas frações. A microestrutura foi constituída basicamente por microagregados intergranulares, com diâmetro médio em torno de 0,12 $\mathrm{mm}$, sem rugosidade, com pedalidade moderada e não acomodados. A fração fina (plasma) mostrou coloração bruno-avermelhada (luz transmitida) e bruno-escura (luz polarizada), de natureza argilosa e sem orientação, correspondendo à contextura-b de birrefringência indiferenciada (Bullock et al., 1985) ou plasma isótico (Brewer, 1976). As frações grosseiras, constituídas basicamente de quartzo, apresentaram-se bem a moderadamente selecionadas com formas arestadas e desarestadas, havendo ainda uma pequena proporção de magnetita ( $5 \%$ da lâmina).

Em alguns pontos da lâmina, verificou-se a presença de áreas com concentrações de argila (material fino) em torno dos grãos de quartzo, caracterizando a contextura-b granoestriada. O espaço poroso ocupou $25 \%$ da superfície da lâmina e foi constituído por canais alongados, preenchidos por raízes, porém sendo comuns os poros tipo empacotamento, cavidades e fissuras. As fissuras estavam presentes na parte inferior da lâmina, apresentando formas alongadas e curvadas, acomodadas, o que caracteriza processos de umedecimento e secagem do solo (Mermut, 1992). Como feição pedológica, destacou-se a presença de pedotúbulos do tipo granotúbulos e agrotúbulos.

A posição $R$ apresentou, de modo geral, características micromorfológicas similares às descritas no ER, diferindo, entretanto, pela diminuição do espaço poroso $(20 \%)$ e pela maior diversidade de poros. Neste ponto de amostragem, houve predominância de poros tipo vesículas na parte superior da lâmina e poros tipo empacotamento

Quadro 2. Propriedades químicas e granulométricas de um Latossolo Vermelho-Amarelo sob pomar de laranja e sob mata

\begin{tabular}{|c|c|c|c|c|c|c|c|c|c|c|c|}
\hline \multirow{2}{*}{ Horizonte } & \multicolumn{3}{|c|}{$\mathbf{p H}$} & \multirow{2}{*}{ M.O } & \multirow{2}{*}{$\mathbf{P}$} & \multirow{2}{*}{$\mathbf{S}$} & \multirow{2}{*}{$\mathbf{T}$} & \multirow{2}{*}{$\mathbf{V}$} & \multicolumn{3}{|c|}{ Granulometria } \\
\hline & $\mathrm{H}_{2} \mathrm{O}$ & $\mathrm{KCl}$ & $\mathrm{CaCl}_{2}$ & & & & & & Areia & Silte & Argila \\
\hline & & & & $\mathrm{g} \mathrm{kg}^{-1}$ & $\mathrm{mg} \mathrm{kg}^{-1}$ & \multicolumn{2}{|c|}{$-\mathrm{mmol}_{\mathrm{c}} \mathrm{kg}^{-1} \ldots$} & $\%$ & $\ldots$ & $-\mathrm{g} \mathrm{kg}^{-1}$ & $\ldots$ \\
\hline \multicolumn{12}{|c|}{ P1 - Área sob pomar de laranja } \\
\hline Ap & 6,0 & 5,5 & 5,7 & 24 & 6 & 45,5 & 62,5 & 73 & 680 & 100 & 220 \\
\hline $\mathrm{AB}$ & 5,9 & 5,4 & 5,7 & 13 & 5 & 28,9 & 42,9 & 67 & 680 & 80 & 240 \\
\hline $\mathrm{BA}$ & 5,8 & 4,9 & 5,3 & 8 & 3 & 16,5 & 35,5 & 46 & 580 & 80 & 340 \\
\hline Bw1 & 5,7 & 5,3 & 5,4 & 6 & 3 & 16,9 & 34,9 & 48 & 600 & 80 & 320 \\
\hline $\mathrm{Bw} 2$ & 5,5 & 5,0 & 5,2 & 10 & 3 & 13,2 & 31,2 & 42 & 620 & 100 & 280 \\
\hline Bw3 & 5,3 & 5,1 & 5,1 & 10 & 2 & 10,9 & 25,9 & 42 & 580 & 120 & 300 \\
\hline \multicolumn{12}{|c|}{ P2 - Área sob mata } \\
\hline A & 6,7 & 6,0 & 5,9 & 36 & 39 & 128,4 & 142,4 & 90 & 660 & 100 & 240 \\
\hline $\mathrm{AB}$ & 6,2 & 5,7 & 5,6 & 17 & 12 & 66,7 & 82,7 & 81 & 660 & 100 & 240 \\
\hline $\mathrm{BA}$ & 6,4 & 5,9 & 5,8 & 6 & 6 & 30,1 & 46,1 & 65 & 660 & 100 & 240 \\
\hline Bw1 & 6,5 & 5,9 & 6,2 & 3 & 6 & 38,7 & 54,7 & 71 & 600 & 80 & 320 \\
\hline Bw2 & 6,1 & 5,7 & 5,8 & 3 & 5 & 22,9 & 38,9 & 59 & 560 & 80 & 360 \\
\hline Bw3 & 5,8 & 4,9 & 5,3 & 8 & 3 & 16,5 & 35,5 & 46 & 560 & 100 & 340 \\
\hline
\end{tabular}


Quadro 3. Resumo das descrições micromorfológicas de um Latossolo Vermelho-Amarelo nas diferentes posições de amostragem sob pomar de laranja (P1) e sob mata (P2), na camada de 0-0,12 m

\begin{tabular}{|c|c|c|c|c|}
\hline & \multicolumn{3}{|c|}{ Perfil 1 - P1 } & \multirow{2}{*}{$\frac{\text { Perfil 2 - P2 }}{\text { Mata }}$} \\
\hline & ER & $\mathbf{R}$ & PC & \\
\hline Geral & $\begin{array}{l}\text { Uma única zona } \\
\text { homogênea. }\end{array}$ & $\begin{array}{l}\text { Uma única zona } \\
\text { homogênea. }\end{array}$ & $\begin{array}{l}\text { Duas zonas distintas, } \\
\text { sendo a mais adensada } \\
\text { localizada na parte } \\
\text { superior da lâmina com } \\
\pm 3,85 \mathrm{~mm} \text { de } \\
\text { espessura. }\end{array}$ & $\begin{array}{l}\text { Uma única zona } \\
\text { homogênea. }\end{array}$ \\
\hline Trama & Porfiro - enáulica. & Porfiro - enáulica. & Porfiro - enáulica. & Porfiro - enáulica. \\
\hline $\begin{array}{l}\text { Microestru- } \\
\text { tura }\end{array}$ & $\begin{array}{l}\text { Microagregados } \\
\text { intergranulares }(30 \%) \\
\text { arredondados, } \\
\text { ondulados com tamanho } \\
\text { médio em torno de } \\
0,12 \mathrm{~mm} \text {. }\end{array}$ & $\begin{array}{l}\text { Microagregados } \\
\text { intergranulares }(30 \%) \text {, } \\
\text { não acomodados, com } \\
\text { tamanho médio em } \\
\text { torno de } 0,15 \mathrm{~mm} .\end{array}$ & $\begin{array}{l}\text { Microagregados } \\
\text { intergranulares, } \\
\text { arredondados e } \\
\text { ondulados com } \\
\text { estrutura primária } \\
(0,04-0,08 \mathrm{~mm}) \text { e } \\
\text { secundária } \\
(0,08-0,20 \mathrm{~mm}) \text {, } \\
\text { totalizando } 20-25 \% \text {. }\end{array}$ & $\begin{array}{l}\text { Microagregados } \\
\text { intergranulares } \\
\text { poliédricos / } \\
\text { arredondados e } \\
\text { coalescidos }(20 \%), \\
\text { variando de } \\
0,038-0,19 \mathrm{~mm} .\end{array}$ \\
\hline $\begin{array}{l}\text { Fração fina } \\
\text { (Plasma) }\end{array}$ & $\begin{array}{l}\text { Coloração bruno sob luz } \\
\text { natural e bruno escuro } \\
\text { em luz polarizada. } \\
\text { Argilominerais com } \\
\text { contextura-b } \\
\text { indiferenciada. }\end{array}$ & $\begin{array}{l}\text { Coloração bruna sob luz } \\
\text { natural e bruno-escura } \\
\text { em luz polarizada. } \\
\text { Argilominerais com } \\
\text { contextura-b } \\
\text { indiferenciada. }\end{array}$ & $\begin{array}{l}\text { Coloração bruno- } \\
\text { avermelhada sob luz } \\
\text { natural e bruno-escura } \\
\text { em luz polarizada. } \\
\text { Argilominerais com } \\
\text { contextura-b } \\
\text { indiferenciada. }\end{array}$ & $\begin{array}{l}\text { Coloração brunò- } \\
\text { avermelhada sob luz } \\
\text { natural e polarizada. } \\
\text { Argilominerais com } \\
\text { contextura-b } \\
\text { indiferenciada. }\end{array}$ \\
\hline $\begin{array}{l}\text { Fração } \\
\text { grosseira } \\
\text { inorgânica }\end{array}$ & $\begin{array}{l}\text { Quartzo }(43 \%) \text { e } \\
\text { magnetita }(2 \%) \\
\text { subangulares e sub- } \\
\text { arredondados ondulados } \\
\text { a lisos variando de } \\
0,04-3,6 \mathrm{~mm} \text {. }\end{array}$ & $\begin{array}{l}\text { Quartzo e magnetita } \\
(50 \%) \text { variando de } \\
0,03-3,19 \mathrm{~mm} \text {, bem } \\
\text { selecionados, } \\
\text { subangulares e sub- } \\
\text { arredondados, } \\
\text { ondulados a lisos. }\end{array}$ & $\begin{array}{l}\text { Quartzo e magnetita } \\
(60 \%) \text {, sub- } \\
\text { arredondados, } \\
\text { subangulares, } \\
\text { ondulados a lisos e } \\
\text { moderadamente } \\
\text { selecionados. }\end{array}$ & $\begin{array}{l}\text { Quartzo e magnetita } \\
(45 \%) \text { sub- } \\
\text { arredondados, } \\
\text { ondulados e mal } \\
\text { selecionados. }\end{array}$ \\
\hline Poros & $\begin{array}{l}50 \% \text { de canais, } 10 \% \text { de } \\
\text { fissuras alongadas e } \\
\text { curvadas, } 10 \% \text { de } \\
\text { cavidades e } 30 \% \\
\text { empilhados, num total } \\
\text { de } 25 \% \text { de poros. }\end{array}$ & $\begin{array}{l}15 \% \text { de fissuras, } 5 \% \text { de } \\
\text { canais, } 40 \% \text { de } \\
\text { vesículas e } 40 \% \text { de } \\
\text { poros de empilhamento, } \\
\text { num total de } 20 \% \text { de } \\
\text { poros. }\end{array}$ & $\begin{array}{l}15 \% \text { de poros na zona } \\
\text { mais adensada e } 20 \% \\
\text { na outra zona. Presença } \\
\text { de vesículas nas duas } \\
\text { áreas. }\end{array}$ & $\begin{array}{l}70 \% \text { de cavidades } \\
(0,038-1,9 \mathrm{~mm}), 30 \% \\
\text { de canais } \\
(1,5-9,5 \mathrm{~mm}), \\
\text { totalizando } 35 \% \text { de } \\
\text { poros. }\end{array}$ \\
\hline $\begin{array}{l}\text { Feições } \\
\text { pedológicas }\end{array}$ & $\begin{array}{l}\text { Ausência de nódulos. } \\
\text { Presença de agro e } \\
\text { granotúbulos } \\
\text { (ortotúbulos), com } \\
\text { forma externa circular e } \\
\text { elíptica, argilosa, } \\
\text { originados de fauna } \\
\text { indeterminada. }\end{array}$ & $\begin{array}{l}2 \% \text { de nódulos típicos } \\
\text { de Fe e Mn com } \\
\text { contraste nítido e forte. } \\
\text { Grano e agrotúbulos } \\
\text { (ortotúbulos), argilosos, } \\
\text { originados de fauna } \\
\text { indeterminada. }\end{array}$ & $\begin{array}{l}\text { Na segunda zona, } \\
\text { ocorre a presença de } \\
\text { nódulos típicos de Fe } \\
(7 \%) \text { e Mn }(3 \%) \text {, sub- } \\
\text { arredondados, variando } \\
\text { de } 0,19-1,54 \mathrm{~mm} \text {. }\end{array}$ & $\begin{array}{l}\text { Nódulos típicos de Fe } \\
\text { (1\%) arredondados/ } \\
\text { ondulados. Agro e } \\
\text { isotúbulos ( } 2 \%), \\
\text { originados de fauna } \\
\text { indeterminada. }\end{array}$ \\
\hline
\end{tabular}

complexo na parte inferior; nesta última posição, foram vistos, ainda, alguns canais (5\%) preenchidos por raízes. Observaram-se, também, áreas com grandes concentrações de plasma, sem orientação, provavelmente provenientes dos processos de compactação do solo.

A principal característica da PC foi a presença de duas zonas distintas, sendo a primeira constituída por uma massa densa, localizada na parte superior da lâmina, com aproximadamente $3,84 \mathrm{~mm}$ de espessura. Nesta zona, os poros ocupavam $15 \%$ da superfície da lâmina e os agregados apresentavamse parcialmente acomodados, com pedalidade variando de forte a moderadamente desenvolvida. A parte inferior caracterizou-se pela maior diversidade de poros, os quais passaram a ocupar $20 \%$ da sua superfície.

Na área sob mata, a porosidade foi caracterizada por cavidades interconectadas e inúmeros canais. Alguns desses canais estão preenchidos por raízes 
em vários estádios de decomposição, ocorrendo, ainda, agrotúbulos e isotúbulos. Os agrotúbulos apresentaram fábrica interna solta contínua, argilosa, discreta e aderente, do tipo ortotúbulo e ocuparam aproximadamente $1,5 \%$ da área da lâmina; provavelmente foram preenchidos a partir do desmoronamento das paredes dos túbulos. Já os isotúbulos apresentaram fábricas internas densas, argilosas, discretas ou aderentes, do tipo metatúbulo, ocupando 0,5 \% da área da lâmina. Essas feições são atribuídas à ação da fauna, já que elas se apresentam preenchidas com materiais provenientes de outros horizontes, decorrentes do remonte biológico. O limite $\mathrm{c} / \mathrm{f}$ foi estabelecido em $2 \mu \mathrm{m}$ para todas as áreas estudadas.

A grande diferença observada nas lâminas de solo deu-se quanto à distribuição do espaço poroso nos diferentes pontos de amostragem (Figura 1).

O ER apresentou predominância de poros tipo canais $(12,5 \%)$ e empacotamento $(7,5 \%)$, ocorrendo em menor quantidade a presença de cavidades e fissuras. A diminuição da porosidade total (PT) no $R$ acarretou o surgimento de poros tipo vesículas, os quais são indicativos de processos de degradação da estrutura do solo. Os bioporos, tipo canais, tiveram o seu volume reduzido em aproximadamente $90 \%$.

A maior diversidade de poros foi encontrada na PC. Nesse ponto, os poros de empacotamento desapareceram, dando origem a poros tipo cavidades e câmaras, os quais estão relacionados com os processos de compactação do solo (Ringrose-Voase \& Bullock, 1984). Os poros oriundos da atividade biológica (bioporos) permaneceram; no entanto,

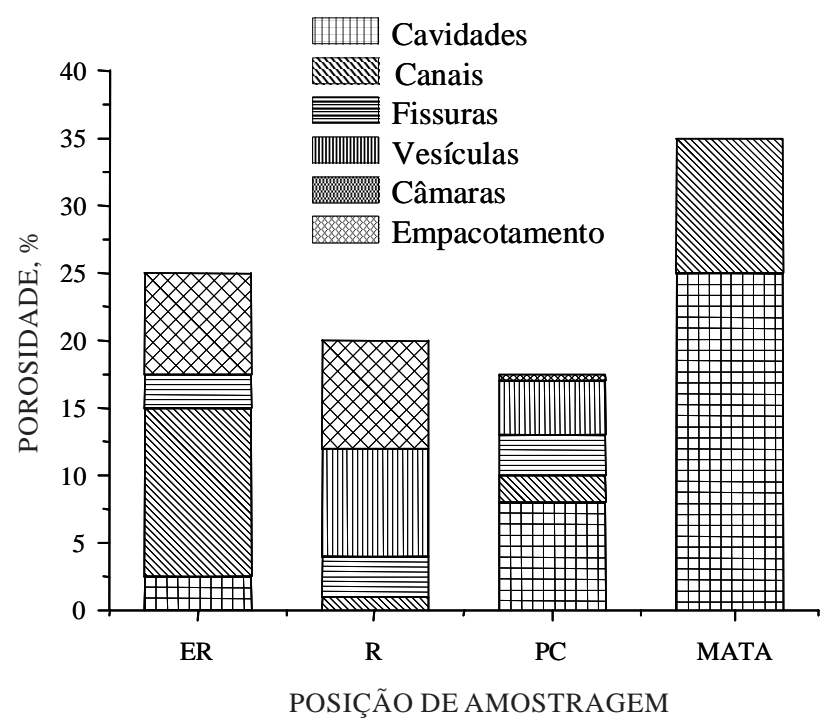

Figura 1. Tipos de poros e porosidade total nas diferentes posições de amostragem de um Latossolo Vermelho-Amarelo sob pomar de laranja (ER, R e PC) e sob mata, na camada de 0,0-12 m. tiveram o seu tamanho reduzido. O desaparecimento dos poros de empacotamento acarretará uma diminuição na condutividade hidráulica do solo, visto que este tem um papel importante no fluxo de água do solo em condições próximas à saturação (Lamandé et al., 2003).

A maior porosidade total foi observada na área sob mata, sendo todos os poros oriundos da atividade biológica. A presença de cavidades nesta área foi atribuída à atividade da fauna do solo (Brewer, 1976). Comparando os dados da PC com a mata, a compactação induzida pelo uso agrícola resultou numa redução de $50 \%$ na porosidade total, aumentando, assim, a diversidade de poros (Figura 1).

A área mais afetada pelo uso agrícola foi a PC, possivelmente em razão da ausência de cobertura vegetal neste ponto de amostragem, como também do fato de a PC ter servido, no início do plantio, como linha de suporte à passagem de máquinas agrícolas. Nesse sentido, a adoção de linhas permanentes deverá contribuir para a manutenção da qualidade física do solo.

Os poros fissurais, que são indicativos de processos de estresse físico no solo, permaneceram constantes nas três posições de amostragem da área sob cultivo (ER, R, PC) (Figura 1). Segundo Pagliai (1987), os poros fissurais e as vesículas são característicos de áreas em processo de degradação da estrutura do solo e encrostamento superficial, em virtude da menor cobertura vegetal do solo.

Os valores da densidade do solo (Ds) (Figura 2) confirmam os dados de distribuição da porosidade (Figura 1), ou seja, os pontos da área sob cultivo que apresentaram menor porosidade total (PT) tiveram os maiores valores de Ds. Isso mostra que a determinação da PT feita por meio de análises micromorfológicas é uma ferramenta confiável para avaliação da estrutura do solo. Conforme Imhoff et al. (2001), a Ds é um dos atributos físicos mais utilizados como indicadores da qualidade estrutural do solo.

Não houve diferença estatística significativa entre os valores de Ds analisados no ER, R e PC na área sob cultivo. A diferença só foi observada quando se comparou a área sob cultivo com a área sob mata, a qual apresentou o menor valor de Ds (Figura 2). Esses resultados foram similares aos obtidos por Lima et al. (2004), pelo teste de compressão uniaxial realizado nos mesmos pontos de amostragem (ER, R e PC), pois não foi observada diferença entre as linhas que separam a curva de compressão secundária (região onde ocorrem as deformações elásticas e recuperáveis) da reta de compressão virgem (deformações plásticas e não-recuperáveis), indicando que os três pontos estudados apresentaram níveis semelhantes de compactação do solo. Esses resultados comprovaram ser o monitoramento das classes de poros mais sensível 


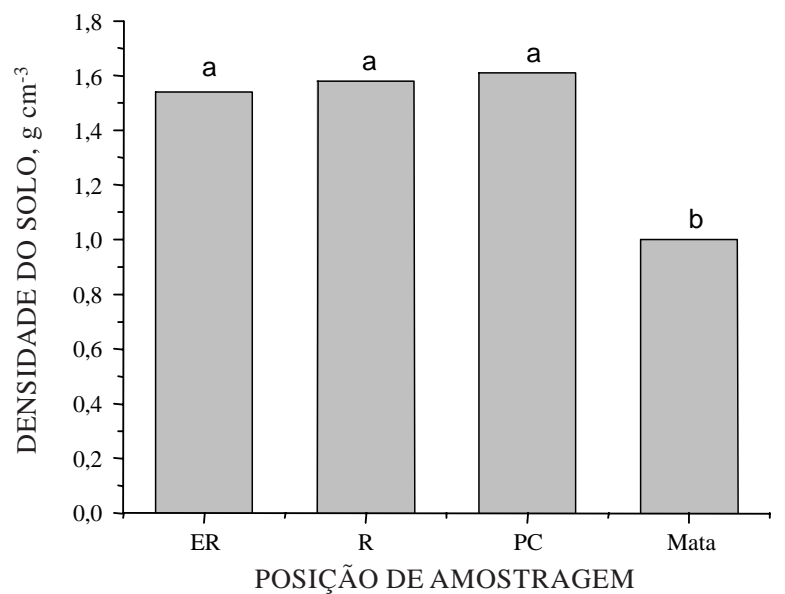

Figura 2. Densidade do solo nas diferentes posições de amostragem de um Latossolo VermelhoAmarelo sob pomar de laranja (ER, R e PC) e sob mata, na camada de $0-0,12 \mathrm{~m}$. Médias seguidas pela mesma letra não diferem entre si pelo teste de Tukey a $5 \%$. para a identificação da deterioração da qualidade estrutural do solo em estádios iniciais.

As fotomicrografias destacaram que, apesar de a posição ER apresentar maior porosidade total na área sob cultivo (Figura 1), foram encontradas evidências de processos de compactação, comprovada pela disposição das raízes no sentido horizontal (Figura 3a). Comparando a posição R (Figura 3b) com a PC (Figura 3c), observou-se que, além dos poros originados pelo processo de compactação (vesículas), houve mudanças no adensamento do plasma. A redução da porosidade em posições mais próximas à linha de cultivo pode ser um fator preocupante, já que a compactação do solo afeta diretamente o desenvolvimento das raízes.

Estudos realizados em área cultivada com laranja, nas posições: linha de cultivo e entrelinha, mostraram que não houve diferença da atividade microbiana, na profundidade de $0-0,20 \mathrm{~m}$, entre os dois pontos analisados (Sanches et al., 1999), evidenciando que a distinção das classes de poros na superfície ocorreu, principalmente, pela atividade da flora do solo, sendo o contrário observado em área sob mata.

A ocorrência da atividade biológica na área de mata foi evidenciada pela presença de pedotúbulos (Figura 3d).

Considerando os resultados obtidos, percebeu-se a diminuição dos bioporos, à medida que as posições de amostragem aproximaram-se da linha de cultivo (ER $>$ R $>$ PC), tendo a mata apresentado a maior porosidade total.
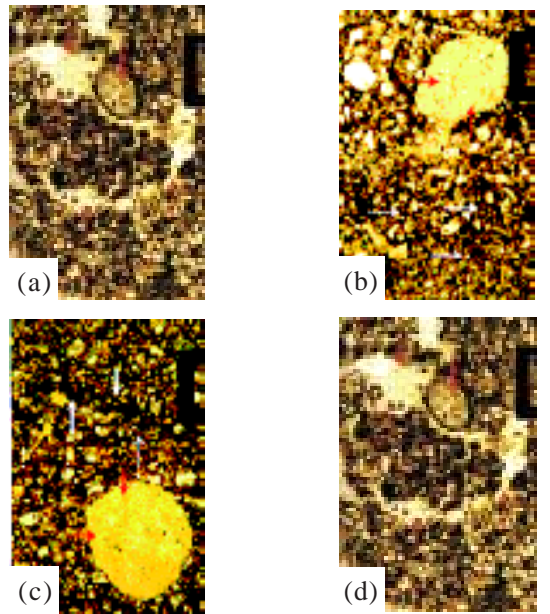

Figura 3. Fotomicrografias de seções delgadas e orientadas de amostras de dois Latossolos Vermelho-Amarelo na camada de 0-0,12 m; (a) posição ER com canais preenchidos por raízes; (b e c) posições R e PC com presença de vesículas; e (d) área sob mata com pedotúbulos (indicados pelas setas vermelhas) oriundos de atividade biológica. As setas vermelhas indicam a presença de bioporos; as brancas, a organização da matriz do solo.

\section{CONCLUSÕES}

1. A compactação superficial causada pela exploração agrícola e pelo tráfego de máquinas afetou, diferencialmente, a forma e a distribuição do espaço poroso, tendo sido os bioporos os mais afetados.

2. O aumento na diversidade de poros mostrouse diretamente relacionado com os processos de degradação da estrutura, sendo o monitoramento dos poros oriundos da atividade biológica (bioporos) um fator essencial para a avaliação das condições estruturais do solo.

3. O estudo da ocorrência das classes de poros mostrou-se mais eficiente na identificação da compactação do solo em estádios iniciais que os dados de densidade do solo.

\section{LITERATURA CITADA}

BLAKE, G.R. \& HARTGE, K.H. Bulk density. In: KLUTE, A., ed. Methods of soil analysis - Physical and mineralogical methods. 2.ed. Madison, ASA/SSSA, 1986. p.363-375.

BREWER, R. Fabric and mineral analysis of soil. New York, Robert E. Krieger, 1976. 428p. 
BULLOCK, P.; FEDOROFF, N.; JONGERIUS, A.; STOOPS, G. \& TURSINA, T. Handbook for soil thin section description. Woverhampton, Waine Research Publishers, 1985. $152 \mathrm{p}$

CASTRO, S.S. Impregnação de amostras de solo para confecção de lâmina delgada. B. Inf. Soc. Bras. Ci. Solo, 31:44, 1985.

CINTRA, F.L.D.; COELHO, Y.S.; CUNHA SOBRINHO, A.P \& PASSOS, O.S. Caracterização física do solo submetido a práticas de manejo em pomar de laranja "Baianinha". Pesq. Agropec. Bras., 18:173-179, 1983.

CURMI, P.; KERTTZMAN, F.F. \& QUEIROZ NETO, J.P. Degradation of structure and hydraulic properties in an Oxisol under cultivation (Brazil). In: RINGROSE-VOASE A.J. \& HUMPHERYS G.S., eds. Soil micromorphology: studies in management and genesis. In: INTERNATIONAL WORKING MEETING ON SOIL MICROMORPHOLOGY, 9., Townsville, 1994. Proceedings. Amsterdam: Elsevier, 1994. p.596-579. (Developments in Soil Science, 22)

GENRO JÚNIOR, S.A.; REINERT, D.J. \& REICHERT, J.M. Variabilidade temporal da resistência à penetração de um Latossolo argiloso sob semeadura direta com rotação de culturas. R. Bras. Ci. Solo, 28:477-484, 2004.

IHMOFF, S.; SILVA, A.P.; DIAS JUNIOR, M.S. \& TORMENA, C.A. Quantificação de pressões críticas para o crescimento das plantas. R. Bras. Ci. Solo, 25:11-18, 2001.

LAMANDÉ, M.; HALLAIRE, V.; CURMI, P.; PÉRÈS, G. \& CLUZEAU, D. Changes of pore morphology, infiltration and earthworm community in a loamy soil under different agricultural managements. Catena, 54:637-649, 2003.

LEMOS, R.C. \& SANTOS, R.D. Manual de descrição e coleta de solos no campo. 3 ed. Campinas, Sociedade Brasileira de Ciência do Solo, 1996. 45p.

LIMA, C.L.R.; SILVA, A.P.; IMHOFF, S.; LIMA, H.V. \& LEÃO, T.P. Heterogeneidade da compactação de um Latossolo Vermelho-Amarelo sob pomar de laranja. R. Bras. Ci. Solo, 28:409-414, 2004.

MERMUT, A.R. Introduction to soil micromorphology. Saskatoon, University of Saskatchewan Department of Soil Science, 1992. 115p.
MERMUT, A.R.; GREVERS, M.C.J. \& DE JONG, E. Evaluation of pores under different management systems by image analysis of clay soils in Saskatchewan, Canada. Geoderma, 53:357-372, 1992.

MIEDEMA, R. Applications of micromorphology of relevance to agronomy. Adv. Agron., 59:119-169, 1997.

PAGLIAI, M. Effects of different management practices on soil structure and surface crusting. Micromorphologie des sols - soil micromorphology. In: INTERNATIONAL WORKING MEETING IN SOIL MICROMORPHOLOGY. Proceedings. Plaisir: Association Française pour L'Étude du Sol, 1987. p.415-421.

RICHARD, G.; BOIZARD, H.; ROGER-ESTRADE, J.; BOIFFIN, J. \& GUÉRIF, J. Effect of compaction on the porosity of a silt soil: influence on unsaturated hydraulic properties. Eur. J. Soil Sci., 52:49-58, 2001.

RINGROSE-VOASE, A.J. \& BULLOCK, P. The automatic recognition and measurement of soil pore types by image analysis and computer programs. J. Soil Sci., 35:673-684, 1984.

RINGROSE-VOASE, A.J. A scheme for the quantitative description of soil macrostructure by image analysis. J. Soil Sci., 38:343-356, 1987.

RINGROSE-VOASE, A.J. Micromorphology of soil structure: description, quantification, application. Aust. J. Soil Res., 29:777-813, 1991.

SANCHES, A.C.; SILVA, A.P.; TORMENA, C.A. \& TRIGOLIN, A.T. Impacto do cultivo de citros em propriedades químicas, densidade do solo e atividade microbiana de um Podzólico Vermelho-Amarelo. R. Bras. Ci. Solo, 23:91-99, 1999.

STOOPS, G. \& JONGERIUS, A. Proposal for a micromorphological classification of soil materials. I. A Classification of related distribution of coarse and fine particles. Geoderma, 13:189-200, 1975.

VANDENBYGAART, A.J.; PROTZ, R.; TOMLIN, A.D. \& MILLER, J.J. Tillage system effects on near-surface soil morphology: Observations from the landscape to microscale in silt loam soils of southwestern Ontario. Soil Till. Res., 51:139-149, 1999. 